\title{
Probing the Transport of Paramagnetic Complexes inside Catalyst Bodies in a Quantitative Manner by Magnetic Resonance Imaging**
}

\author{
Jaap A. Bergwerff, Anna A. Lysova, Leticia Espinosa Alonso, Igor V. Koptyug, and \\ Bert M. Weckhuysen*
}

Supported metal and metal oxide catalysts form an important class of functional materials, owing to their role in oil refining, the manufacturing of bulk and fine chemicals, and as automotive catalysts. ${ }^{[1]}$ As the first step in the industrial preparation of supported catalysts, regardless of the nature of the active phase, a metal-precursor salt is usually applied to the mm-sized support bodies by pore-volume impregnation with a suitable precursor solution, after which drying, calcination, and in some cases reduction or sulfidation, is carried out to obtain the active catalyst. To maximize the metal loading in the final catalyst, metal salts with a high solubility, such as nitrates, are often used as the precursor in industrial impregnation solutions. ${ }^{[2]}$ For example, the impregnation solutions used in copper-based methanol-synthesis catalysts, nickel-based hydrogenation catalysts, cobalt-based Fischer-Tropsch catalysts, and iron-based ammonia synthesis catalysts, contain paramagnetic $\mathrm{Cu}^{2+}\left(\mathrm{d}^{9}\right), \mathrm{Ni}^{2+}\left(\mathrm{d}^{8}\right), \mathrm{Co}^{2+}\left(\mathrm{d}^{7}\right)$, and $\mathrm{Fe}^{3+}\left(\mathrm{d}^{5}\right)$ ions, respectively. ${ }^{[1]}$

The macro-distribution of the active phase in the catalyst bodies is an important parameter. Although a homogeneous distribution is often desired to maximize the dispersion, the formation of egg-shell catalysts may be advantageous if the aim is to limit the transport length of reactants and products. ${ }^{[3]}$ Unfortunately, conventional methods to determine quantitative metal-distribution profiles inside catalyst bodies are only applicable to dried material and often only allow postsynthesis evaluation of the material. Magnetic resonance

[*] Dr. J. A. Bergwerff, L. Espinosa Alonso, Prof. Dr. B. M. Weckhuysen Inorganic Chemistry and Catalysis group

Department of Chemistry

Faculty of $\beta$ Sciences

Sorbonnelaan 16, 3854 CA, Utrecht (the Netherlands)

Fax: $(+31)$ 30-251-1027

E-mail: b.m.weckhuysen@chem.uu.nl

Dr. A. A. Lysova

Boreskov Institute of Catalysis

SB RAS 5 Lavrent'ev Prospekt

Novosibirsk 630090 (Russia)

Dr. A. A. Lysova, Prof. Dr. I. V. Koptyug

International Tomography Center SB RAS

3A Institutskaya Street, Novosibirsk 630090 (Russia)

[**] B.M.W. acknowledges financial support by Albemarle Catalysts and the Dutch Science Foundation (NWO-CW-VICl grant). I.V.K and A.A.L. thank RFBR (grant 05-03-32472), RAS (grants 5.2.3, 5.1.1), SB RAS (Integration grant 11), the Russian President's program of support of the leading scientific schools (grant NSch-4821.2006.3) and the Russian Science Support Foundation for financial support. A.A.L. acknowledges the Global Energy Foundation and the Council on Grants of the President of the Russian Federation (MK5135.2007.3 grant). imaging (MRI) offers the possibility to monitor the preparation of supported catalyst bodies in a non-invasive manner and could therefore be a valuable addition to the catalyst characterization toolbox. ${ }^{[4]}$

It has recently been shown that the distribution of different components, such as phosphate, inside catalyst bodies could be imaged using the MRI approach by probing NMR-active nuclei (e.g. $\left.{ }^{31} \mathrm{P}\right) \cdot{ }^{[5]}$ Herein, a novel approach is taken in which quantitative distribution profiles of paramagnetic metal-ion complexes inside catalyst bodies can be indirectly deduced from ${ }^{1} \mathrm{H}$ MRI images of the water protons. In this way, the dynamics of the transport of the metalprecursor inside a single support body can be monitored online, allowing for a better control of the preparation process. $^{[6,7]}$

After impregnation of porous support bodies, an aqueous solution is generally taken up instantaneously by the support through capillary action. Metal-ion complexes and other ingredients in the impregnation solution are transported with the flow of the solution towards the center of the support bodies. However, components that adsorb onto the support surface will be contained near the external surface. ${ }^{[8,9]} \mathrm{A}$ concentration gradient is established over the catalyst bodies, which can only be overcome by desorption of the compounds from the support surface, and subsequent diffusion through the pore system. Hence, it may take considerable time before equilibration is complete and an ageing step is generally applied after impregnation in industrial catalyst preparation.

Since imbibition of the impregnation solution by the support is practically instantaneous, the concentration of protons in the extrudates after impregnation may be considered homogeneous throughout the sample. It is now possible to exploit the influence of different components in the impregnation solution on the ${ }^{1} \mathrm{H}$ NMR signal to derive their distribution. In this study, the detrimental effect of the presence of paramagnetic complexes on the strength of the ${ }^{1} \mathrm{H}$ NMR signal of the water inside the pores of support bodies was evaluated. This effect was subsequently used to determine the distribution of these paramagnetic nuclei inside impregnated support bodies through ${ }^{1} \mathrm{H}$ MRI measurements. As a proof of principle, the transport of $\mathrm{Co}^{2+}$ complexes inside $\mathrm{Al}_{2} \mathrm{O}_{3}$ extrudates after impregnation with $\mathrm{Co}\left(\mathrm{NO}_{3}\right)_{2}$ solutions was monitored, however, the method is generally applicable since the same approach has been successfully applied for $\mathrm{Cu}^{2+}$ and $\mathrm{Ni}^{2+}$ ions.

Two-dimensional (2D) ${ }^{1} \mathrm{H}$ MRI images were recorded on extrudates after impregnation with solutions of different $\mathrm{Co}^{2+}$-ion concentrations (Figure 1) as were one-dimensional (1D) profiles of the ${ }^{1} \mathrm{H}$ NMR signal intensity as a function of 


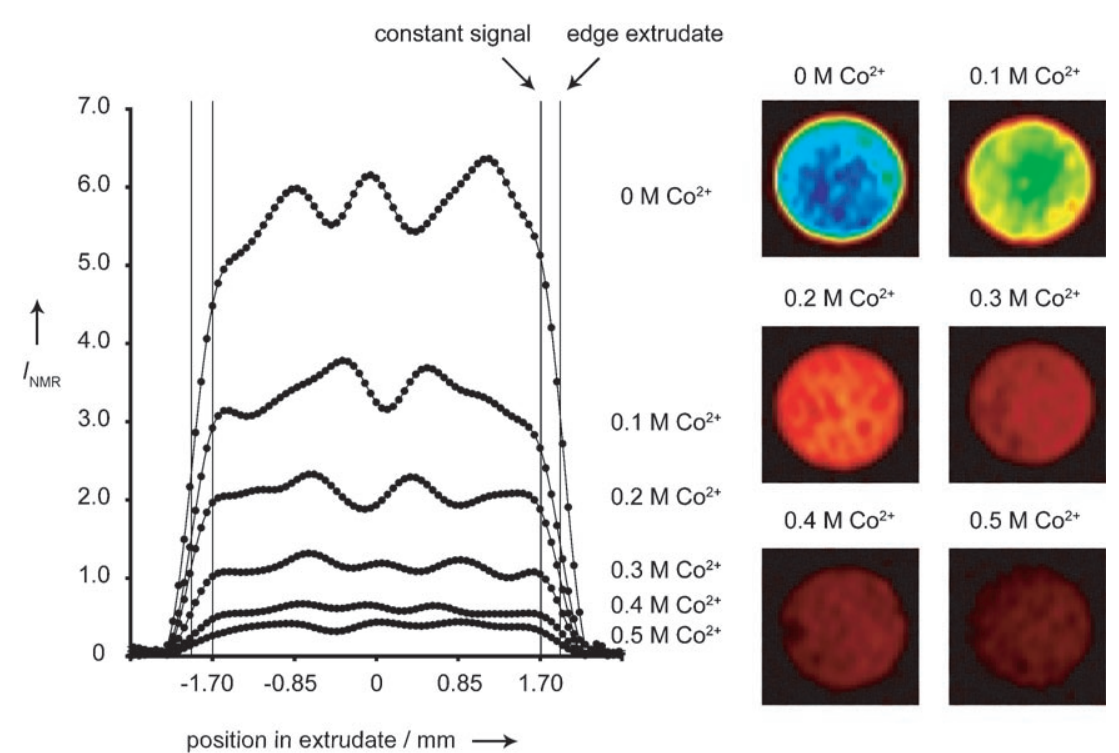

Figure 1. Right: $2 \mathrm{D}{ }^{1} \mathrm{H}$ MRI images of $\mathrm{Al}_{2} \mathrm{O}_{3}$ extrudates $15 \mathrm{~h}$ after impregnation with solutions of different cobalt-ion concentrations; blue: high ${ }^{1} \mathrm{H}$ NMR signal (a low $\mathrm{Co}^{2+}$ concentration) red: low ${ }^{1} \mathrm{H}$ NMR signal (a high $\mathrm{Co}^{2+}$ concentration). Left: the 1D profiles of the ${ }^{7} \mathrm{H}$ NMR signal intensity $\left(I_{\mathrm{NMR}}\right)$ as a function of the location inside the extrudates. for the signal intensity as a function of the $\mathrm{Co}^{2+}$-ion concentration are shown in Figure 2. The experimental error induced by the measurement procedure and inhomogeneities in the pore structure within a single extrudate could be evaluated by determining the standard deviation of the measured values for the ${ }^{1} \mathrm{H}$ NMR signal intensity along the diameter of an extrudate. The $95 \%$ probability interval is represented by the error bars in Figure 2. The data points could be fitted with a thirdorder polynomial, as indicated in the graph, yielding an empiric correlation, which makes it possible to quantify the amount of $\mathrm{Co}^{2+}$ ion at a specific position in the extrudate as a function of time. Since parameters, such as the chemical nature and the texture of the support (e.g. pore volume and average pore diameter), influence the ${ }^{1} \mathrm{H}$ NMR signal intensity, this correlation has no further physical meaning. ${ }^{[10]}$ A similar calibration procedure is therefore required for quantitative meas-

position inside the extrudates (Figure 1). To ensure that the distribution of the metal-ion complexes was homogeneous in these samples the material was allowed to age overnight after impregnation. It can be seen that the average ${ }^{1} \mathrm{H}$ NMR signal intensity decreased with increasing $\mathrm{Co}^{2+}$-ion concentration in the impregnation solution (Figure 1). The ${ }^{1} \mathrm{H}$ NMR signal is most intense in the $1 \mathrm{D}$ profile of the water-filled extrudate. The signal obtained from the inside of the extrudate varies as a function of the location, which can be explained by inhomogeneities in the extrudates. In certain areas, voids may for instance be present, leading to a higher local concentration of water. In the corresponding 2D images, a high ${ }^{1} \mathrm{H}$ NMR signal (a low $\mathrm{Co}^{2+}$ concentration) is indicated by a blue color and a low signal (a high $\mathrm{Co}^{2+}$ concentration) by a red color. When the $2 \mathrm{D}{ }^{1} \mathrm{H}$ MRI image is compared to the actual dimensions of the extrudate, the sample appears smaller than in reality, as a result of suppression of the signal towards the outer surface of the extrudate. The positions of the edges of the extrudate and the boundaries of the area for which a reasonably constant ${ }^{1} \mathrm{H}$ NMR signal is observed are indicated in the $1 \mathrm{D}$ profiles in Figure 1. Compared to the protons of $\mathrm{H}_{2} \mathrm{O}$ molecules in solution, the relaxation times of water protons inside the $\mathrm{Al}_{2} \mathrm{O}_{3}$ pore system are shorter owing to the loss in mobility and the presence of paramagnetic impurities in the support. As a result of these short relaxation times, a high repetition time can be used in the MRI measurements to minimize the time required for the acquisition of one image. However, water protons in the periphery of the extrudates may be less influenced by the $\mathrm{Al}_{2} \mathrm{O}_{3}$ and their relaxation could be slower. Owing to the fast repetition time, the signal from protons with long relaxation times could be suppressed.

The average ${ }^{1} \mathrm{H}$ NMR signal intensity for positions inside the impregnated extrudates was calculated for the solutions with different $\mathrm{Co}^{2+}$-ion concentrations. The resulting values

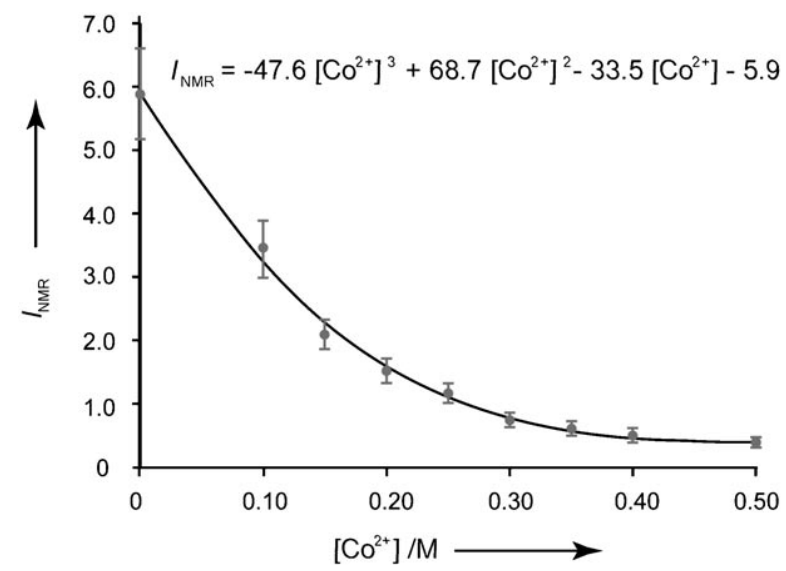

Figure 2. Correlation between the $\mathrm{Co}^{2+}$-ion concentration in the impregnation solution and the average ${ }^{1} \mathrm{H}$ NMR signal intensity obtained from impregnated extrudates. The error bars indicate the average values for the ${ }^{1} \mathrm{H}$ NMR signal intensity in the 1D profiles plus and minus two times the standard deviation. The fit curve corresponds to the equation given.

urements on the transport of paramagnetic metal ions in different supports. The ${ }^{1} \mathrm{H}$ NMR signal is almost completely suppressed after impregnation with a $0.50 \mathrm{M} \mathrm{Co}\left(\mathrm{NO}_{3}\right)_{2}$ solution; this concentration thus defines the detection limit of this method for $\left[\mathrm{Co}\left(\mathrm{H}_{2} \mathrm{O}\right)_{6}\right]^{2+}$ complexes.

The transport of $\left[\mathrm{Co}\left(\mathrm{H}_{2} \mathrm{O}\right)_{6}\right]^{2+}$ was monitored after impregnation of the extrudates with a $0.20 \mathrm{M} \mathrm{Co}^{2+}$-ion solution. The 2D ${ }^{1} \mathrm{H}$ MRI images recorded at different times after impregnation are shown in Figure 3. The transport of $\mathrm{Co}^{2+}$ complexes can be observed as the area with high NMR signal intensity near the center of the extrudates (where no $\mathrm{Co}^{2+}$ cations are present) decreases as a function of time 


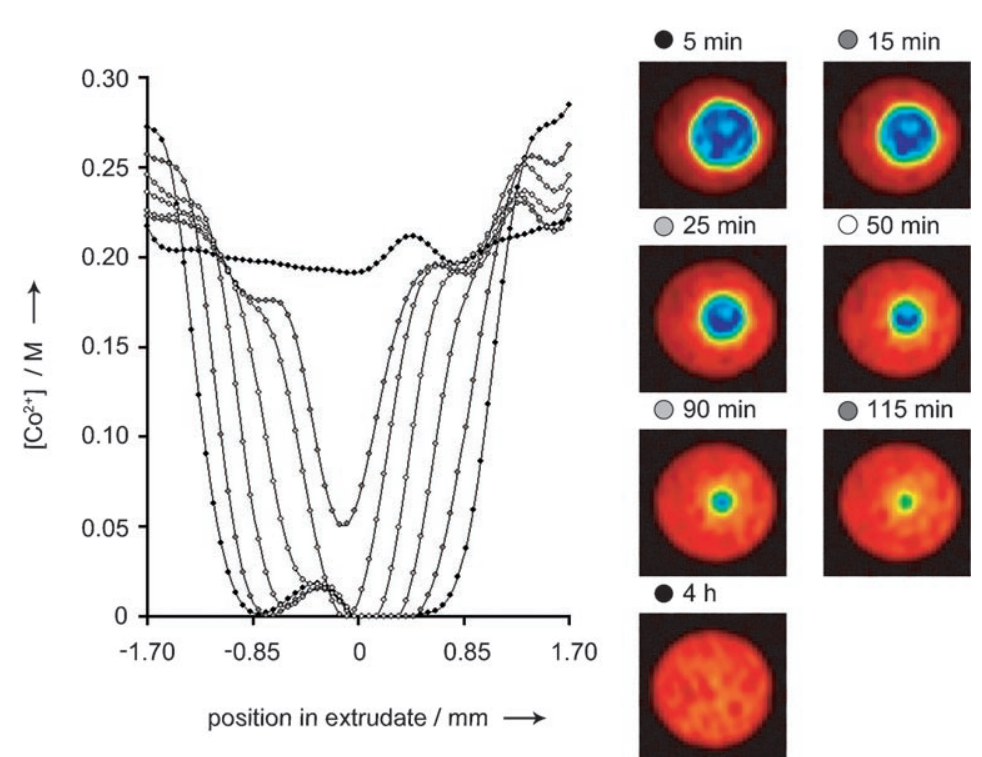

Figure 3. Right: 2D ${ }^{1} \mathrm{H}$ MRI images of an $\mathrm{Al}_{2} \mathrm{O}_{3}$ extrudate at several times after impregnation with a $0.20 \mathrm{M} \mathrm{Co}\left(\mathrm{NO}_{3}\right)_{2}$ solution; colors as in Figure 1. Left: Quantitative $\mathrm{Co}^{2+}$-ion distribution plots, derived from the 2D images (see text for details).

after impregnation. Using the calibration curve presented in Figure 2, the $1 \mathrm{D}{ }^{1} \mathrm{H}$ NMR signal intensity profiles could be transformed into quantitative distribution profiles, which are presented on the left in the same figure.

From these $\mathrm{Co}^{2+}$-ion profiles, a two-step transport of $\left[\mathrm{Co}\left(\mathrm{H}_{2} \mathrm{O}\right)_{6}\right]^{2+}$ can clearly be observed. Immediately after impregnation, $\mathrm{Co}^{2+}$ complexes are only present in a ring approximately $0.70-\mathrm{mm}$ thick near the external surface of the extrudates. The $\left[\mathrm{Co}\left(\mathrm{H}_{2} \mathrm{O}\right)_{6}\right]^{2+}$ complexes are transported into the $\mathrm{Al}_{2} \mathrm{O}_{3}$ pore system by the convective flow of solution. Adsorption of these complexes on the $\mathrm{Al}_{2} \mathrm{O}_{3}$ surface occurs as one or more $\mathrm{H}_{2} \mathrm{O}$ ligands are exchanged by support oxygen atoms. ${ }^{[11,12]}$ Since no excess solution was applied to the extrudates, the total amount of cobalt inside a single extrudate remains constant after impregnation. Directly after impregnation, all $\mathrm{Co}^{2+}$-ion complexes are in the outer shell of the extrudates. As a result, their concentration inside the pores is higher than $0.20 \mathrm{M}$ at these positions. When equilibration proceeds, $\left[\mathrm{Co}\left(\mathrm{H}_{2} \mathrm{O}\right)_{6}\right]^{2+}$ complexes diffuse from the external areas towards the center of the extrudates. A protruding cobalt-front is observed, while the concentration of cobalt near the edges of the extrudates decreases over time. Eventually, after $4 \mathrm{~h}$, a homogeneous distribution of $\mathrm{Co}^{2+}$-ion complexes is observed.

The MRI technique presented herein offers great potential for researchers in both academia and industry who aim at a more controlled preparation of supported metal (oxide) catalyst bodies since it is generally applicable to study the preparation of a wide range of catalytic systems containing paramagnetic metal ions. From a practical point of view, the technique allows the moment at which drying should be started to obtain a certain type of metal-ion distribution to be determined with great accuracy. In addition, the measurements provide invaluable input for models describing the distribution of metal-ion complexes inside catalyst bodies as a function of different parameters in the preparation process. Through the MRI method, the adsorption and diffusion behavior of industrially relevant metal-ion complexes in a specific support material can be assessed in a single experiment. However, in the imaging mode the total ${ }^{1} \mathrm{H}$ NMR intensity is used for signal detection, chemical information that can normally be obtained from NMR spectroscopy is lost, thus the use of molecular spectroscopy in a spatially resolved manner can provide valuable complementary information, since, in this way, the nature of the metal-ion complexes can be probed as well. ${ }^{[13-16]}$ Based on this combination of techniques, a detailed molecular picture of the physicochemical processes taking place during the preparation of catalyst bodies can be drawn.

\section{Experimental Section}

Materials: Cylindrical $\gamma-\mathrm{Al}_{2} \mathrm{O}_{3}$ extrudates with a diameter of $3.85 \mathrm{~mm}$ and an average length of $12 \mathrm{~mm}$ were used. The pore volume of this material is $0.39 \mathrm{mLg}^{-1}$ and its surface area is $140 \mathrm{~m}^{2} \mathrm{~g}^{-1}$. Aqueous solutions of $\mathrm{Co}\left(\mathrm{NO}_{3}\right)_{2} \cdot 6 \mathrm{H}_{2} \mathrm{O}$ (Acros Organics, p.a.) were used for impregnation.

Sample preparation: Pore-volume impregnation was carried out on single extrudates. Care was taken that the extrudates were completely wetted with the solution. To prevent the formation of air bubbles in the extrudates, the impregnation solution was applied from one side first.

MRI measurements: A Bruker Avance DRX $300 \mathrm{MHz}$ wide-bore spectrometer with imaging accessories was used for the MRI measurements. 2D images were recorded using a two-pulse spinecho sequence. In the ${ }^{1} \mathrm{H}$ MRI measurements, slice selection was applied to record the signal from 2-mm thick slices of the extrudates. Frequency encoding was applied in the $x$ direction yielding a spatial resolution of $139 \mu \mathrm{m}$ for ${ }^{1} \mathrm{H}$ MRI measurements. The application of phase encoding gradients in the $y$ direction resulted in a spatial resolution of $231 \mu \mathrm{m}$ in this direction in the ${ }^{1} \mathrm{H}$ MRI images. The acquisition time of a single image was $4 \mathrm{~min}$.

Received: March 31, 2007

Published online: June 25, 2007

Keywords: cobalt · heterogeneous catalysis - MRI . supported catalysts

[1] a) Preparation of Solid Catalysts (Eds.: G. Ertl, H. Knozinger, J. Weitkamp), Wiley-VCH, Weinheim, 1999; b) J. Hagen, Industrial Catalysis: A Practical Approach, Wiley-VCH, Weinheim, 1999; c) H. F. Rase, Handbook of Commercial Catalysts, CRC Press, New York, 2000; d) Catalyst preparation: Science and Engineering (Ed.: J. Regalbuto), CRC Press, Boca Raton, 2007.

[2] a) K. Bourikas, C. Kordulis, A. Lycourghiotis, Catal. Rev. Sci. Eng. 2006, 48, 363-444; b) W. A. Spieker, J. Liu, X. Hao, J. T. Miller, A. J. Kropf, J. R. Regalbuto, Appl. Catal. A 2003, 243, 53-66; c) W. A. Spieker, J. R. Regalbuto, Chem. Eng. Sci. 2001, 56, 3491-3504; d) J. A. Bergwerff, M. Jansen, R. G. Leliveld, T. Visser, K. P. de Jong, B. M. Weckhuysen, J. Catal. 2006, 243, $292-302$.

[3] a) E. Iglesia, Appl. Catal. A 1997, 161, 59-78; b) L. G. A. van de Water, L. G. Bezemer, J. A. Bergwerff, M. VersluijsHelder, B. M. Weckhuysen, K. P. De Jong, J. Catal. 2006, 242, 
287-298; c) A. Y. Khodakov, W. Chu, P. Fongarland, Chem. Rev. 2007, 107, 1692-1744.

[4] a) P. T. Callaghan, Principles of Nuclear Magnetic Resonance Microscopy, Clarendon Press, Oxford, 1995; b) I. V. Koptyug, L. Y. Khitrina, V. N. Parmon, R. Z. Sagdeev, Magn. Reson. Imaging 2001, 19, 531-534.

[5] A. A. Lysova, I. V. Koptyug, R. Z. Sagdeev, V. N. Parmon, J. A. Bergwerff, B. M. Weckhuysen, J. Am. Chem. Soc. 2005, 127, $11916-11917$.

[6] R. Schlögl, S. B. Abd Hamid, Angew. Chem. 2004, 116, $1656-$ 1667; Angew. Chem. Int. Ed. 2004, 43, 1628-1637.

[7] A. T. Bell, Science 2003, 299, 1688-1691.

[8] S. Y. Lee, R. Aris, Catal. Rev. Sci. Eng. 1985, 27, 207-340.

[9] A. V. Neimark, L. I. Kheifez, V. B. Fenelonov, Ind. Eng. Chem. Prod. Res. Dev. 1981, 20, 439-450.

[10] I. V. Koptyug, S. I. Kabanikhin, K. T. Iskakov, V. B. Fenelonov, L. Yu. Khitrina, R. Z. Sagdeev, V. N. Parmon, Chem. Eng. Sci. 2000, $55,1559-1571$.
[11] V. Vivier, F. Aguey, J. Fournier, J. F. Lambert, F. Bedioui, M. Che, J. Phys. Chem. B 2006, 110, 900-906.

[12] J. Vakros, K. Bourikas, S. Perlepes, C. Kordulis, A. Lycourghiotis, Langmuir 2004, 20, 10542-10550.

[13] J. A. Bergwerff, L. G. A. van de Water, T. Visser, P. de Peinder, B. R. G. Leliveld, K. P. de Jong, B. M. Weckhuysen, Chem. Eur. J. 2005, 11, 4591-4601.

[14] J. A. Bergwerff, T. Visser, R. G. Leliveld, B. A. Rossenaar, K. P. de Jong, B. M. Weckhuysen, J. Am. Chem. Soc. 2004, 126, $14548-14556$.

[15] L. G. A. van de Water, J. A. Bergwerff, T. A. Nijhuis, K. P. de Jong, B. M. Weckhuysen, J. Am. Chem. Soc. 2005, 127, 5024-5025.

[16] T. Mang, B. Breitscheidel, P. Polanek, H. Knozinger, Appl. Catal. A 1993, 106, 239-258. 